Sección Uno: Ensayo

Retos y Experiencias en la Construcción de Paz.

\title{
Ideas de los Pastos para construir la paz en Nariño, Colombia ${ }^{1}$
}

Ideas from the Pastos indigenous group to build peace in Nariño, Colombia

Edgar Guillermo Mesa Manosalva

Facultad de Ciencias de la Educación

Universidad de Nariño (Colombia)

manosalva50@gmail.com

\section{Resumen}

Este artículo, fruto del proyecto de investigación "Aportes étnico-culturales y educativos de docentes de la Universidad de Nariño para construir la paz en el postconflicto ${ }^{2 "}$, vincula las cosmovisiones: pachamama, minga colectiva, religiosidad popular, el cuento pastuso, el carnaval de negros y blancos y las prácticas ancestrales socioeconómicas de los Pastos, con la finalidad de valorar y sistematizar ideas para construir la paz en la región.

Para tal propósito se adoptó la metodología cualitativa etnográfica, utilizando como técnicas de recolección de datos la revisión documental, la observación participante y la entrevista en profundidad, tomando como base la información que suministraron campesinos de las distintas localidades de la región, docentes universitarios, familiares y amigos. Se concluye que las ideas procedentes de las cosmovisiones y prácticas ancestrales conforman un nutrido sistema de valores sociales, económicos, religiosos, políticos y culturales fundamentales para la construcción de la paz regional.

\begin{abstract}
This article, as a result of the research Project called "Educational, ethnic-cultural contributions from University of Nariño faculty in order to build peace in the post-conflict" links the "Pachamama" world view, the "Minga", the popular religious beliefs, regional tales, the Black and White carnivals and the ancient socio-economic practices with the purpose of

\footnotetext{
${ }^{1}$ Recibido: 30/03/2018 Evaluado: 01/05/2018 Aceptado: 25/06/2018

${ }^{2}$ Proyecto de Tesis Doctoral, Facultad de Ciencias de la Educación, Universidad de Granada, España, dirigida por los Doctores Sebastián Sánchez Fernández, Universidad de Granada y Eulogio García Vallinas, Universidad de Cádiz, España.
} 
valuing and structuring the necessary ideas to build peace in the region. For such purpose, the Qualitative-Ethnographic research methodology used in this document was adopted, applying techniques such as document review, participant observation and in-depth interviews. All of this was based on the information provided by peasants from all over the region, University staff, relatives and friends. The main ideas coming from ancient cultures world view and their traditional practices create a large system of social, economic, religious, political and cultural values which are essential for the construction of regional peace.

Palabras clave: Cosmovisiones, Prácticas Ancestrales, Construcción de Paz.

Keywords: World view, traditional practices, peace construction.

\section{Introducción}

En el marco del posconflicto, el país se prepara para construir una paz estable y duradera, la cual posibilite soñar con una Colombia sin conflicto que marque nuevas pautas para la convivencia y el desarrollo de las regiones. Surgen por tanto iniciativas como la aquí planteada, esto es, rescatar las cosmovisiones étnico-culturales y las prácticas socioeconómicas ancestrales que, tras un análisis cuidadoso, aporten conocimientos, saberes y estrategias pedagógicas para la construcción de paz. Así pues, se articula a la propuesta concepciones como la de pachamama, minga colectiva, religiosidad popular, el cuento pastuso y el carnaval de negros y blancos que, en su estructura teórico-práctica, contienen elementos valiosos que aportan a este propósito y que por tanto es necesario conocer, comprender, interpretar y transmitir. En este punto, la participación del Estado, de las comunidades, de la iglesia, de las organizaciones sociales, de los colectivos y, sobre todo, de las instituciones educativas se hace necesaria para la formulación de lo que podría llamarse una pedagogía para la paz.

Conviene subrayar que la paz es un proceso que permea todo el tejido social y que requiere de procesos formativos no desde una educación deshumanizada sino desde una educación inclusiva, equitativa, social, crítica, liberadora y transformadora. La estrategia de la educación para la paz promueve la formación en valores, la noviolencia, la prevención de los conflictos, el respeto a los derechos humanos, la equidad de género y la participación democrática, aspectos constitutivos de la Cultura de Paz.

En este sentido, la hermenéutica de la paz posibilitó la articulación de saberes y conocimientos, prácticas sociales y valores, para entender y comprender las tramas socioculturales y políticas de los pueblos y su papel protagónico en la construcción de paz en el posconflicto. En consecuencia, se propone este artículo en el que se describen y analizan las cosmovisiones y prácticas ancestrales de los Pastos y sus aportes conceptuales para construir la paz en la región. 


\section{Metodología}

Para lograr los resultados esperados se planteó el objetivo general en perspectiva interpretativa y comprensiva de las cosmovisiones étnico-culturales, las prácticas educativas y la cultura de paz desde el paradigma cualitativo etnográfico. Afirma Martínez (1999) que "La investigación cualitativa busca la comprensión e interpretación de la realidad humana y social, con un interés práctico, es decir con el propósito de ubicar y orientar la acción humana y su realidad subjetiva" (p. 62). "Se busca examinar la realidad tal como otros la experimentan, a partir de la interpretación de sus propios significados, sentimientos, creencias y valores" (p. 63), se "aborda a profundidad experiencias, interacciones, creencias y pensamientos presentes en una situación específica y la manera como son expresadas" (Torres, 1995, p. 109), “intenta hacer una aproximación global de las situaciones sociales para explotarlas, describirlas y comprenderlas de manera inductiva. (Bonilla y Rodríguez, 2000, p.70)

Por otra parte, Martínez (1999) considera que:

El enfoque etnográfico se apoya en la convicción en que las tradiciones, roles, valores y normas del ambiente en que se vive se van internalizando poco a poco y generan regularidades que pueden explicar la conducta individual y de grupo en forma adecuada. En efecto, los miembros de un grupo étnico, cultural o situacional comparten una estructura lógica o de razonamiento que, por lo general, no es explícita, pero que se manifiesta en diferentes aspectos de la vida. (p.30)

Así las cosas, este paradigma ofrece una metodología en relación directa con la hermenéutica y la interacción social lo cual permitió recolectar datos, explorar las relaciones sociales y describir la realidad tal como la viven las personas que participaron en esta investigación. De este modo fue posible indagar a profundidad el comportamiento humano a través de varias muestras, cinco docentes de la Universidad de Nariño, familias de Pupiales, Puerres, Guachucal, Túquerres y Pasto, tres localidades de Pasto: cujacal, el campanero y Casanare y personas cercanas y amigas pertenecientes a los Pastos.

El estudio se desarrolló en un periodo de tres años, tiempo en el que se realizaron observaciones participantes, entrevistas en profundidad, charlas informales y revisión documental, con el propósito de recoger la información necesaria y posible, para sistematizarla y analizarla; luego, elaborar categorías y subcategorías; y, finalmente, proceder a la interpretación y a la teorización.

\section{Resultados}

Los resultados presentados a continuación se centran en la información obtenida en cada una de las fases de la investigación. Ésta permitió hacer aproximaciones al entorno de la comunidad en estudio, a sus cosmovisiones y prácticas socioeconómicas ancestrales. 
Respecto al entorno, los Pastos, que desde épocas precolombinas tienen asiento en la región andina, se ubican al suroccidente de Colombia en el departamento de Nariño. De acuerdo con Mamián (2004) "ocupan esta franja transversal del sur de Colombia y norte de Ecuador y que tiene como centro el nudo de Huaca o de los Pastos" (p.24). Así mismo, Afanador (2011) afirma que "Llegaron desde el sur hacia la zona central de los Andes y se localizaron en el espacio geográfico comprendido entre el rio Chota (Ecuador) al sur, hasta el actual municipio de Ancuya (Colombia) y el rio curiaco localizado entre los municipios de Tangua y Funes; principalmente en el nudo de los Pastos (p.12).

Los Pastos conciben el mundo como una totalidad; Así, cada una de sus partes o elementos son fundamentales para el funcionamiento del todo, en perfecta armonía y equilibrio. En este sentido, hay que mencionar que el género humano es parte esencial de ese todo y para que pueda existir es importante la comunicación, el respeto, la reciprocidad y la complementariedad con el universo. Sobre el particular, Huanacuni (2010) recuerda que "En gran parte de los pueblos de la región andina de Colombia, Ecuador, Bolivia, Perú, Chile y Argentina (...) pervive la cosmovisión ancestral o visión cósmica, que es una forma de comprender el mundo y expresarse en las relaciones de vida (...) con una esencia común: el paradigma comunitario basado en la vida en armonía y el equilibrio con el entorno (p.63)".

También Bajtín (1987) lo afirma al postular que "la sucesión de las estaciones, la siembra, la concepción, la muerte y el crecimiento, son los componentes de esta vida productora. La noción implícita del tiempo contenida en esas antiquísimas imágenes es la noción del tiempo cíclico de la vida natural y biológica (p.11)”.

En cuanto a las cosmovisiones, es decir, la manera de ver e interpretar el mundo, Muñoz (1998) señala que son "un conjunto de ideas que articulan y ordenan los valores y las ideas de una sociedad, e indirectamente, hacia las cuales se proyectan las prácticas" (p.14); de manera semejante Geertz (2003) afirma que son "un sistema de concepciones expresadas en formas simbólicas por medio de las cuales la gente se comunica, perpetúa y desarrolla su conocimiento sobre las actitudes hacia la vida" (p.144). Es notorio, entonces, que cada sociedad en su proceso de desarrollo configura el modo de pensar, sentir y actuar de manera dinámica, pues ordena los pensamientos, aclara los sentimientos y regula los comportamientos de acuerdo con "esquemas culturales-religiosos, filosóficos, estéticos, científicos y lingüísticos, son procedimientos que, en definitiva, suministran patrones o modelos para organizar los procesos actitudinales y conductuales sociales y personales" (Muñoz, 1998, p.14). En este sentido las cosmovisiones étnico-culturales se constituyen en referentes teórico-prácticos para construir la paz en Nariño.

\section{Cosmovisiones y prácticas ancestrales de los Pastos}

Entre las cosmovisiones y prácticas ancestrales de los Pastos, que aportaron al objetivo del presente estudio, se resaltan las siguientes:

\section{Pachamama y paz}

Esta cosmovisión se fundamenta en el concepto espacio/tiempo y se recrea en la madre tierra. Puede entenderse desde una concepción cíclica que se autogobierna con el ayer, el hoy y el 
mañana en el devenir infinito. Los conceptos más importantes se agrupan en torno a unidad, reciprocidad, armonía, complementariedad, dualidad, transversalidad, tierra, chagra, naturaleza y universo. A continuación, se abordarán algunos de ellos.

El concepto de unidad gravita sobre la idea de que la pachamama es un cuerpo viviente compuesto por partes en mutua relación, el todo y las partes, nada está por fuera de la pachamama, todo nace y descansa en ella, es decir nada falta, ni nada sobra. En este punto, el concepto de unidad se articula con el de las prácticas ancestrales: la chagra y el entreverado. Por lo que respecta a la primera, Mamián (2004) la concibe como "la práctica de crear y vivir mundos universalmente reducidos, a la manera de fractales, donde el hombre andino fundamentó su agricultura, su cultura y su mundo, porque para él, la chagra es su universo y el universo es la chagra" (p.112). La filosofía del entreverado, por su parte, es la habilidad para entender, generar y desarrollar la vida a partir de la reciprocidad, a través de la complementariedad, la alternancia, el turno o la mediación (simétrica o asimétrica), "entre los seres diferenciados, opuestos o antagónicos, reconociendo y reconociéndose, que cada uno (suelo, clima, agua, animales, plantas, parientes, sol, luna, santos, mamitas, etc.) o como comunidades (naturales, humanas, telúrico-celestes), tienen su valor, su jerarquía, sus potencialidades e insuficiencias" (p.113).

Por consiguiente, Valladolid (1993) citado por Mamián (2004) dice que "la filosofía de la chagra y el entreverado justifica mucho más el decir que para los andinos el mundo es una totalidad de seres inteligentes y sensibles en la que no se los comprende separados sino íntimamente relacionados, cualquier evento se entiende inmerso dentro de los demás y cada parte refleja el todo (p.113).

Porque la "totalidad es la colectividad pacha, que comprende el conjunto de comunidades vivas, diversas y variables, cada una de las cuales a su vez representa el todo" (Mamián, 2004, p.113).

Dentro de este "universo y universalidad agrario-andinos (...) entreverados en el universo de la chagra, entre el destino, la necesidad o la casualidad, clandestinos como un secreto, están los productos misios" (Mamián, 2004, p.114): presencia de dos colores contrastados, generalmente mitad y mitad, referidos a los productos agrarios y artesanales de la comunidad. Entonces, misiar es la acción de dar un producto agrario de dos colores contrastados, para fundar y recrear la reciprocidad.

Se entiende la reciprocidad como una idea ancestral que involucra a todos los seres; dado que todos somos parte de la pachamama somos parientes unos de otros. A diferencia de las cosas y de los animales, el ser humano proviene del vientre de una madre, del útero materno, de la calidez humana y ésta es su primera y más grande experiencia. En este particular, "la mujer está ligada directamente a lo más complejo del universo, que es la vida" (Boff, 2006, p.20). La impronta maternal perdura en la memoria del ser humano porque con su leche alimenta su ser biológico, con sus palabras transmite su idioma, con sus caricias y arrullos enseña el lenguaje del amor, con sus manos suaves y delicadas participa el arte y con estas maneras lo adorna de finuras filosóficas, estéticas, éticas, lingüísticas, culinarias y manifestaciones artísticas propias de su cultura. 
La reciprocidad comporta la armonía y el equilibrio, éste nace de la relación de las partes con el todo al mantener un punto de energía en la actividad gravitacional del universo. Sólo se alteraría con la acción destructiva del ser humano. Del equilibrio deviene la armonía, que es la correspondencia adecuada entre las acciones del hombre con la naturaleza, se refiere al accionar del hombre en la transformación de los contextos para su bienestar y felicidad. Pero cuando el egoísmo, la avaricia y la lujuria imperan sobre la razón y la emoción, la actividad del ser humano se desborda y se corrompe; por esto, el principio de reciprocidad recobra su significado y sentido porque hay que devolverle a la naturaleza lo que de ella hemos tomado, hay que restituirle lo que nos ha dado, hay que compensarle lo que hemos gastado, es decir, practicar la corresponsabilidad para garantizar la armonía y el equilibrio no sólo de la pachamama en sentido físico-natural, sino también de la comunidad en sentido relacionalsocial.

La pachamama es una entidad natural que provee de lo necesario a los seres vivientes y al género humano y en ese recibir se inscribe 'para dar recibir', es decir, el dar para recibir y el recibir para dar, en una dinámica cotidiana, recibo lo que me da la naturaleza y de lo que recibo doy a otros. En este mismo sentido, la complementariedad alude a la capacidad de perfeccionar o complementar algo que no está funcionando bien. En términos de las relaciones sociales, las personas se complementan en sus capacidades y funciones, en la agricultura, por ejemplo, los cultivos necesitan abonos, apoyos y a veces combinaciones de semillas para su crecimiento. Los seres humanos somos seres completos-incompletos, perfectos-imperfectos, no por esto perversos, malos o egoístas, sino seres llamados a encontrar la realización humana, la vocación, la felicidad y la dignidad.

Así mismo la madre tierra provee los recursos, los medios, las semillas y los frutos para que el ser humano se beneficie y disfrute de ellos, para que aprenda a trabajar y alimentar a su familia. El trabajo es la actividad física, mental y emocional para transformar el medio natural para su bienestar, para su felicidad y para la dignidad humana. El trabajo lo convierte en un hacedor de productos, conocimientos y experiencias que le garantizan la sostenibilidad familiar y social.

Entonces la pachamama y el bien común son una sola realidad, son la base del bienestar social, pues el bien común es darle a cada uno lo que necesita para vivir con dignidad y ésta es la mejor y mayor expresión de justicia social y la base para la construcción de paz. En el concepto de bien común también se incluyen los servicios y los recursos, por esto el Estado tiene la obligación de ofrecerlos y garantizarlos a todas las personas. Al respecto, la Carta Encíclica 'Laudato Sí' (2015) afirma:

El bien común presupone el respeto a la persona humana en cuanto tal, con derechos básicos e inalienables ordenado a su desarrollo integral. También reclama el bienestar social y el desarrollo de los diversos grupos intermedios, aplicando el principio de la subsidiariedad. Entre ellos destaca especialmente la familia, como célula básica de la sociedad (...) El bien común requiere la paz social.

El bien común no es algo exclusivamente humano, sino de toda la comunidad cósmica. "Todo cuanto existe y vive merece existir, vivir y convivir. El bien común particular surge partiendo 
de la sintonía y sinergia con la dinámica del bien común planetario y universal" (Boff, 2013, p.25).

Habría que decir también que en la cosmovisión pachamama, el concepto de armonía hace referencia a un estado en el cual el género humano interactúa con la madre naturaleza de manera responsable, sin alterar los ritmos, sin hacer saltos en los procesos y sin abusar de los recursos. Lo anterior por cuanto la naturaleza es un ser vivo, determinado por sus propias leyes, que evoluciona de acuerdo con unos ciclos que la renuevan constantemente, independientemente de la actividad humana.

Finalmente, cabe retomar el concepto de complementariedad el cual enseña que el género humano necesita de la madre tierra pues su vida depende absolutamente de la naturaleza. Por ello, el hombre está llamado a cuidar, proteger, renovar, recrear y conservar los recursos que son la vida misma, disponiendo todas sus capacidades al servicio de la madre tierra pues con su accionar la mejora o la destruye. En este sentido, una idea fuerte para la construcción de la paz está relacionada con sostenibilidad y sustentabilidad de los recursos naturales. La ecología integral es inseparable de la noción de bien común, un principio que cumple un rol central y unificador en la ética social entendida como "el conjunto de condiciones de la vida social que hacen posible a las asociaciones y a cada uno de sus miembros el logro más pleno y más fácil de la propia perfección” (Laudato Sí, 2015).

Entonces en la cosmovisión de la pachamama se recrean y se enriquecen los conceptos de equilibrio, armonía, reciprocidad y complementariedad. De ahí nace el concepto de bien común, bienestar social, justicia social y se deriva la dimensión económica, laboral y productiva. Estos conceptos recobran nuevas significaciones para la construcción de paz. "la pachamama es la madre tierra que lo provee todo, y no se la puede ni se la debe contaminar, deforestar, herir, dañar o destruir" (e1d5p7:5,10) $)^{3}$, "el respeto a la naturaleza filosóficamente hablando es el respeto al otro" (e1d1p1:13,41), "hay que implementar nuevas formas de vivir" (e1d2p3:12,28), es necesario concebir un modelo económico alternativo que si bien es cierto, requiere del uso de la naturaleza, no debe afectarla en su estructura, en su funcionamiento y en su vida, luego entonces, "la condición está en no considerar la naturaleza como un bien de cambio, una mercancía, sino como un bien de uso" (e1d2p3:1,17).

\section{Minga y paz}

La cosmovisión Minga o manos prestadas se entiende como ayuda, solidaridad, servicio y tejido social. Esta concepción es esencial para la ayuda mutua, pues desde ella se fundamentan las relaciones sociales y familiares. Es un accionar ancestral a través del cual se mantiene una economía basada en el trabajo colaborativo. En tiempos de cosecha, en el enteje de una casa, en la construcción de una obra social, en la limpieza de caminos, por ejemplo, se necesitan manos y brazos, y a cambio de la ayuda se reciben alimentos o parte de la cosecha; de esa manera todos tienen lo básico para subsistir.

Es necesario recalcar que la solidaridad es un valor importante y está directamente relacionado con las manos prestadas, es decir, que, gracias a una labor prestada, quien

\footnotetext{
${ }^{3}$ Estas citas corresponden a las entrevistas realizadas a los docentes de la Universidad de Nariño.
} 
necesite recibe algo para el beneficio propio y el de su familia, no es asistencialismo, más bien, es un concepto atado al trabajo, en el sentido en que la madre tierra da lo necesario para vivir, entonces cada uno debe trabajar para conseguir el sustento. No ocurre lo mismo con el holgazán quien al no prestar sus manos para algo útil no merece recompensa alguna. La caridad no es dar por dar, también está relacionada a recibir para dar, es un ir y venir de una acción solidaria. Se ayuda a los huérfanos, a las madres abandonadas, a los ancianos y a los desvalidos.

En la dinámica de las comunidades se propician los matrimonios de miembros de distintas localidades para favorecer el intercambio de bienes, productos y servicios, de esa manera garantizar el bienestar de las familias, especialmente de los hijos. Esta dinámica en ascenso oxigena las relaciones parentales y posibilita interacciones sanas y fecundas. En pocas palabras, la minga simbolizada en las manos prestadas la ayuda mutua, el servicio desinteresado, el trabajo colectivo, la solidaridad y refuerza el entramado social fuente de su estructura socio política. La minga "también puede ayudar a construir la paz porque es solidaridad, servicio y bienestar social" (e1d5p7:6,12), "construir la paz es construir la vida y desde la minga se construye la vida" (e1d1p1:25,70).

En consecuencia, de la cosmovisión pachamama y minga se desprenden acciones económicas que fundamentan el tejido social y el buen vivir. La madre tierra ofrece todos los recursos y materiales; el ser humano con su inteligencia y trabajo consigue los frutos para vivir; mediante la práctica de las manos prestadas se consolidan las relaciones sociales necesarias para la vida comunitaria y familiar. Entonces, el buen vivir no está relacionado directamente con el tener más, sino con la satisfacción del disfrute de lo que la madre tierra da en comunión con los demás. El sentido de lo comunitario es necesario y representa identidad, con lo cual se alimenta la idea de pertenencia y se sostiene el significado de la alteridad.

Las comunidades, en este sentido, practican la reciprocidad en términos de alteridad, porque en las actividades agrícolas, económicas y comerciales tienen en cuenta al otro en su necesidad, por ello son importantes las acciones colectivas que describe Mamián (2004):

"La payacua que consiste en ir a donde están cosechando, llevándole al dueño de la cosecha algo que necesite en su labor inmediata, y él corresponde con lo de su cosecha" (p.63). Al mingante dueño de brazo o trabajo hay que darle, para que lleve de la cosecha, lo mejor, lo escogido, que él mismo escoge; esta acción, "es lo que se llama ración o las escogidas, cuya medida es la milla o el millado, es decir, lo que alcanza en la punta doblada del pañolón, en el caso de la mujer, o del poncho (ruana) en el caso del hombre" (p.63). El agrado es el regalo que se lleva a un pariente o amigo que visita porque hay que compartir de lo que Dios da. El misiar consiste en que si por casualidad, en una cosecha, se encuentra un producto (papa, oca, maíz, etc.) de colores contrastados, se lo entrevera con los normales y se lo lleva como regalo a un compadre, amigo o pariente que viva en el espacio alterno; "el que lo recibe sin darse cuenta, queda misiado, que quiere decir, entre otras cosas, que al año siguiente tiene que donarle productos de su cosecha" (p.63).

Las recogidas se refieren al "acto establecido como posibilidad y derecho, que realizan las mujeres, los ancianos y los niños, de acercarse donde estén cosechando y, detrás, ir recogiendo lo que sin proponérselo los cosechadores van dejando" (p.63). A quienes tienen 
esta costumbre, también se les denomina chuliadores. Es decir, la minga colectiva se podría resumir en lo siguiente, "le presto mis manos, usted no me paga, pero cuando yo tenga la necesidad usted me presta las suyas" (e1d1p1:24, 68).

\section{Religiosidad y paz}

En la relación del ser humano con la naturaleza se suscitan imaginarios colectivos acerca de lo religioso, lo sagrado, lo divino, lo espiritual que da origen a las manifestaciones y prácticas cultuales, rituales y ceremoniales, este es el origen de la religiosidad de casi todos los pueblos. Según Mamián (2004) "entre las comunidades de tradición Pasto, la religión y la religiosidad no se dan como la devoción y el temor individual a un dios o a unos santos, o como la adhesión a dogmas y creencias escriturarios" (p.105). "El mundo de lo imaginario está constituido por las múltiples relaciones del hombre con su mundo circundante y está inmerso en las diversas representaciones y prácticas sociales” (Rodríguez, 2005, p.17).

Históricamente el encuentro entre culturas se dio a través de un proceso de aculturación e imposición de una sobre otra, originando el coloniaje y mestizaje. Durante este periodo se mezclaron aspectos de las diferentes religiones, dando origen a la religiosidad popular desde la cual el pueblo creyente expresa su fe. Los misioneros españoles para adoctrinar a los pueblos retomaron elementos de la cultura nativa y los juntaron con elementos de la doctrina cristiana; en el transcurrir del tiempo, se mezclaron de tal manera que hoy es imposible hacer separaciones porque es una mezcla compacta, sólida, fecunda. Así, el origen de la religiosidad popular es un fenómeno cultural conocido como sincretismo religioso que propicia la mezcla de aspectos sagrados y paganos para expresar la fe y las creencias.

Es a través de la religiosidad popular que la gente expresa sus valores religiosos a pesar de no tener conocimiento de los dogmas de la Iglesia Católica o del significado de los sacramentos, a las personas le interesa dar gracias por las lluvias, por el sol, por las fases de la luna, por el viento, por los insectos, por la siembra, la cosecha, etc. En esta dinámica se tejen algunos valores morales que configuran ideas acerca del bien y del mal, tales como justicia, libertad, bien común, bondad, amor, amistad, maldad, egoísmo, envidia, odio, entre otros, los cuales son valores y antivalores que dirigen las actitudes, comportamientos y conductas personales, familiares y sociales.

En perspectiva cristiana, la doctrina se sostiene en tres aspectos: amor, perdón y caridad. Lo que significa que el cristianismo es un estilo de vida basado en el amor como la primera condición para vivir el mensaje de Cristo; el perdón como la condición para reparar las acciones provenientes del egoísmo, el odio y la venganza; y la caridad como la actitud de servicio y entrega a la humanidad, sin la cual no es posible el amor. No obstante, en el proceso del sincretismo religioso, no todo ha sido claro y transparente porque se ha privilegiado más la norma, el dogma, el castigo que el amor, el perdón y la caridad. En consecuencia, la iglesia católica y las iglesias protestantes están llamadas a construir en lugar de destruir, a unir en lugar de separar, a sumar en vez de dividir y a transmitir en lugar de tergiversar el verdadero mensaje del evangelio. En este sentido y en la perspectiva religiosa, no hay cabida para los odios interreligiosos, ni para los fanatismos divisionistas, ni para los fundamentalismos terroristas; por el contrario, hay espacio para el diálogo ecuménico, para las celebraciones colectivas y para los encuentros fraternales. 
Resulta de interés social en el Acuerdo Final entre el Gobierno y las Farc (2017), el capítulo sobre las víctimas del conflicto en Colombia: Sistema integral de verdad, justicia, reparación y no repetición, porque las víctimas tienen derecho a saber la verdad de los hechos, a un tiempo de reconciliación y perdón, a la reparación de los daños sufridos y a la no repetición de los hechos nunca más. Este proceso que puede resultar largo y doloroso es necesario para curar las heridas, borrar las huellas del odio, el rencor, la venganza y establecer los cimientos preparados para la construcción de justicia y paz.

De ahí que la fe sea un valor que impulse la confianza, el optimismo, la esperanza y promueva el servicio al prójimo, es decir, el que está próximo: el vecino, la comadre, el padrino, la ahijada, el yerno, la nuera, la abuela, la suegra... la comunidad. Por consiguiente, ser cristiano significa ser testigo de la revelación de Dios a la humanidad y practicar el amor, el perdón y la caridad, de donde se infiere que la religiosidad implica un potencial de liberación integral que debe hacerse efectiva.

\section{Humor y paz}

En el sur occidente colombiano, especialmente en los andes nariñenses, el cuento pastuso es un elemento importante de la identidad cultural. El cuento es un dicho, una ocurrencia o historia breve, narrada o dibujada que contiene un doble sentido, una burla o una ironía. El humor es una expresión artística cuya función es el entretenimiento y la risa.

En el cuento pastuso, aparecen tres elementos distintivos, que de acuerdo con Montenegro (2002) son: contenido, origen y objeto del cuento. El contenido del chiste "es la burla del atraso de un grupo humano que sufre un notable aislamiento y un evidente rezago económico en el contexto de un país que se moderniza en forma acelerada" (p.215). En su origen, "son responsables ciertos grupos que acaban de acceder a la modernización y que, con frecuencia, a través de la burla, expresan la inseguridad propia de quienes han adquirido recientemente su condición de personas modernas" (p.216). Y el más importante, el objeto del chiste: "los pastusos, que sólo pueden explicarse a partir de los rasgos característicos de este grupo humano, así como de su peculiar historia de enfrentamientos y desencuentros con el resto del país" (p.217).

Buena parte de la cultura de los Pastos lleva la impronta de la cultura incaica, en el quichua, las fiestas, la gastronomía, el arte, las siembras, los productos, etc., y esta impronta es precisamente lo que hace que el pastuso sea diferente al resto del país. Montenegro (2002) afirma que "los pastusos exhiben rasgos culturales que difieren claramente de los del resto del país" (p.224). Los pastusos en general "siempre se sintieron más próximos a Ecuador y al resto de Suramérica", y "probablemente su característica más distintiva sea su manera de hablar, con un lenguaje salpicado incluso de términos quechuas" (p.224).

Del mismo modo Sanz (2002) afirma:

El quechua es la única lengua de América del Sur que en la época precolombina desempeñó el papel de "lengua de civilización". Propagada por los conquistadores incaicos, se difundió sucesivamente por todo el vasto imperio (...) los conquistadores y colonizadores españoles, para fines de servicio y de administración, trajeron desde 
Quito a muchos centenares de indios (hombres y mujeres) de habla quechua (dialecto quichua), llamados yanaconas (sirvientes). Un gran número de ellos se quedó en estas tierras y contribuyó a enriquecer el habla local con quechuismos. (p. 17)

En consecuencia, el cuento pastuso reúne historia, modernización, identidad y regionalismo, por esto posibilita la risa, la alegría y el esparcimiento. Por otra parte, el humor genera la idea optimista acerca de que la vida hay que vivirla con entusiasmo, aprendiendo a disfrutar y gozar cada momento, cada situación, entendiendo las adversidades como oportunidades y no como fracasos. También, permite entender que la vida es una sola, aquí y ahora, por tanto, es menester saberla vivir en la cotidianidad de la existencia.

La concepción humorista enseña que la alegría es un ingrediente fundamental de la existencia humana, que es necesario expresar los sentimientos placenteros, que es bueno sonreír, mantener un buen estado de ánimo, porque ello dispone a las personas al diálogo, a la escucha, a la tolerancia, a la solidaridad y a la paz. Las personas alegres contagian a otras, las personas optimistas abren puertas, las personas sonrientes animan a los tristes, es decir, el buen humor serena los ánimos, predispone el espíritu y activa la creatividad.

Por todo esto, las pequeñas acciones, las risas compartidas y las celebraciones colectivas son la base para la felicidad, entendida como los instantes de profunda satisfacción personal, a través de los cuales las metas se van cumpliendo y el proyecto de vida se va realizando. En este sentido, para construir la paz se necesitan dosis de optimismo, dedicación, compromiso, tolerancia, amor, servicio y mucha alegría.

\section{Carnaval y paz}

El carnaval es un ritual festivo, una expresión de la cultura popular, una oportunidad para el arte, la estética, la ética y "un maravilloso escenario para el encuentro intercultural" (Mesa, 2016, p.3). Bajtín (1987) afirma que "es la segunda vida del pueblo, basada en el principio de la risa. Es su vida festiva" (p.8), Así mismo, la Unesco (2003) dice que: "los rituales y las fiestas suelen celebrarse en momentos y lugares especiales, y recuerdan a la comunidad aspectos de su visión del mundo y su historia" (p.2). Es una fiesta colectiva en donde unos y otros se reúnen para celebrar la vida, sin distingos sociales, ni abolengos, ni cargos públicos, es la fiesta de todos. Se vive a través del juego, es jugando que se celebra el carnaval, echando talco, untando cosméticos, persiguiendo al otro, bailando aquí y allá; en el juego colectivo está la esencia, por esto es una oportunidad para la tolerancia, el respeto, la igualdad y la construcción de ambientes sanos, positivos y pacíficos.

Entonces es un ritual festivo que se repite cada año de manera cíclica, rememora el pasado, confiere significado al presente y vislumbra el futuro. Así, se constituye en un acto simbólico y de memoria colectiva, se enriquece de los conocimientos, experiencias y visiones de las nuevas generaciones. En este sentido, el carnaval es el escenario para el diálogo intercultural porque participan todos los rostros étnicos y todas las expresiones culturales de la región, es decir, la multiculturalidad se regocija en el abrazo fraterno y le confiere trascendencia a la pluralidad, a la conflictividad y a la complejidad, aspectos constitutivos de la interculturalidad. 
En definitiva, la celebración carnavalesca es una convocatoria a la paz, a la fiesta pacífica y al goce colectivo, por esto "el carnaval es un territorio de paz porque aquí llega Raimundo y todo el mundo" (e1d3p5:49,75), es la evocación de la hora de recreo en la escuela, todos esperaban ese momento para disfrutar del juego, de la merienda, de la risa, la alegría y el júbilo. Aprender a jugar jugando es maravilloso porque cada uno aporta al juego, pero cuando no se entiende bien y no se cumplen las normas del juego, el mismo grupo llama la atención. Estos momentos de tolerancia son fundamentales para continuar el juego. En este sentido, la tolerancia es un valor muy cercano a la amistad, al compañerismo, al paisanaje; estos "espacios de tolerancia son lecciones de paz, eso hay que aprenderlo" (e1d3p5:50,75).

Por consiguiente, el carnaval es el juego de la vida, en su celebración se viven todas las experiencias posibles, o como dice la canción: La vida es un carnaval, de Celia Cruz (1998): "Ay, no hay que llorar, que la vida es un carnaval, que es más bello vivir cantando. Ooo ay, no hay que llorar, que la vida es un carnaval, y las penas se van cantando". En el carnaval "la creatividad sale a flote, se revive esa idiosincrasia, esa riqueza cultural que tenemos, esa riqueza artística, musical, linguiística, todo, el carnaval es una expresión concentrada de esta cultura que puede ser una herramienta, un instrumento eficaz para la construcción de paz en el posconflicto (e1d1p1:38,97)".

En definitiva, el carnaval es el tejido social por excelencia, alimentado por los hilos de la estética, ética, economía, política y religión que juntas conforman la urdimbre de la cultura, por la cual pasan las tramas de la existencia.

\section{Buen vivir y paz}

Desde el punto de vista geopolítico, el departamento de Nariño ofrece múltiples posibilidades al desarrollo regional. El océano pacífico es un potencial infinito de riquezas, pero está abandonado y olvidado, la zona andina biodiversa y con todos los pisos términos ofrece variedad de productos durante todo el año, lo mismo la ganadería, la cuyicultura, la avicultura, la piscicultura, la minería, el turismo entre muchos otros, pero se necesita la asistencia técnica, financiera y administrativa del Estado pues advierten un potencial socioeconómico de vastas proporciones para el desarrollo y progreso de la región, "la diversidad cultural es tan necesaria para el género humano como la diversidad biológica para los organismos vivos" (Unesco, 2001, art.1).

A pesar del abandono y olvido por parte del Estado, en la región andina nariñense, los conflictos son abordados desde las cosmovisiones y prácticas ancestrales de los pueblos. De la pachamama proviene el concepto del bien común, bienestar socioeconómico y por esta razón se favorece el minifundio como derecho a la tierra, el derecho a que cada familia tenga su chagra o parcela para que la cultive y produzca alimentos para la familia.

De igual manera la concepción de la minga enriquece la idea de ayuda, solidaridad y servicio mediante las manos prestadas, fortalece el tejido social a través de la amigancia, compadrazgo y parentesco, y se constituye en el pilar de la estructura social y económica de los Pastos, entonces, de la pachamama y la minga proviene la filosofía del buen vivir. Es decir, el buen vivir del sumak kawsai (en quechua) y suma qamaña (en aymara) tiene "relación directa y dinámica con el interés colectivo, con la minga social y cultural, con una 
idea integradora de la comunidad y el territorio" (Hernández, 2015, p.61). Además, "supone una visión holística e integrada del ser humano con el aire, el agua, los suelos, las montañas, los árboles, los animales y el universo, obteniendo así permanente armonía con todo" (Rojas, 2013, p.123).

El buen vivir hace referencia a la realización ideal y hermosa del planeta y a una vida digna en plenitud. A diferencia de otras alternativas como el bien vivir, vivir mejor o mejor vivir, la tradición indígena ha legado a la sociedad una relación de equilibrio, complementariedad y armonía con la naturaleza en perspectiva social y comunitaria, es decir, tomar lo necesario, retribuir y complementar para el cuidado, la preservación, la sostenibilidad y la sustentabilidad de la madre tierra.

Para los Pastos, el enfoque del buen vivir resulta central como un referente integral en la formulación del "plan de acción y vida, [el cual] tiene bases en una opción y estilo de vida alternativo, con componentes que rompen el actual paradigma hegemónico de progreso dominante de occidente" (Calpa, 2011, p.). Es un proceso constructivo y acumulativo que resulta de la combinación adecuada de formas históricas de habitar el territorio, desplegando acciones fraternales y solidarias en todos los lugares de encuentro y vida tanto individuales y colectivas, así como el impulso a cambios cualitativos de las significaciones imaginarias. En definitiva, Hernández (2015) afirma que "recuperar el sentido de una ruta del buen vivir, toma forma cuando el territorio, sus colectividades y su cultura, empiecen a tener cauce en una nueva dinámica de relaciones políticas sociales, económicas y administrativas caracterizadas por la horizontalidad, la descentralización autonómica de los territorios y regiones" (p.63)

De acuerdo con lo anterior y desde una concepción histórica, la paz "debe surgir de la condición del ser nariñense, de una idiosincrasia, de un modo de ser y pensar, de unas circunstancias y condiciones históricas concretas" (Hernández, 2015, p.63), de actitudes de respeto a la diferencia, al territorio, al sentido consuetudinario de justicia, a los saberes ancestrales, a una educación propia, a la medicina tradicional, pues "el camino del respeto de la diversidad no es el de unificar, sino es el de crear-primero que todo-una concepción de mundo" (Zambrano, 2006, p.10) ya que en estas realidades se han regulado pacíficamente los conflictos, y siempre han estado "ligadas con una esfera más amplia del buen vivir" (Muñoz, 2004, p.8).

De este modo, la paz surge y se desarrolla desde una base impregnada de "interculturalidad étnica, que caracteriza el desarrollo humano de los sujetos que habitan, construyen y se relacionan directamente en el territorio y que configuran un tejido social único, una forma particular de ver el mundo" (Hernández, 2015, p.64).

Todo lo dicho anteriormente tiene su fundamento en la Cultura de Paz, la cual "consiste en una serie de valores, actitudes y comportamientos que rechazan la violencia y previenen los conflictos tratando de atacar sus causas para solucionar los problemas mediante el diálogo y la negociación entre las personas, los grupos y las naciones" (Unesco, 1998, Resolución A/52/13). El programa de Acción sobre una Cultura de Paz (1999) la promueve por medio de la educación, lo cual indica que el abordaje de la paz es un asunto educativo y que en 
términos curriculares se tiene que asumir como el eje transversal de todos los contenidos y prácticas escolares (Zaragoza, 2003; Muñoz, 2004; Sánchez, 2014; García Vallinas, 2010).

\section{Conclusiones}

Las cosmovisiones de los Pastos son un conjunto de principios, valores, conceptos y prácticas que enriquecen y fortalecen la organización social, económica, política y educativa de las comunidades de la región andina nariñense. Son marcos constitutivos de la cultura que recrean las concepciones filosóficas, estéticas, éticas y comportamentales de los individuos y de los pueblos.

El concepto de pachamama valora la unidad, la armonía, la reciprocidad y la complementariedad como principios de la productividad, la sostenibilidad medioambiental, la seguridad y la soberanía alimentaria de los pueblos mientras la minga fortalece las relaciones sociales, favorece la economía familiar, fomenta el respeto a la diferencia, enriquece el buen vivir y es la base de la organización sociocultural de las comunidades.

En la misma línea, las festividades nos recuerdan los ciclos vitales de la existencia, las celebraciones de corta y larga duración, las interacciones sociales y trascendentes y la vivencia del eterno retorno.

Una tarea impostergable de todas las entidades educativas será el fomento de una educación basada en los derechos humanos, en principios y valores contextualizados y orientados hacia una praxis comunitaria, social y pacífica.

Así las cosas, consolidar la Cultura de Paz en todas las instituciones educativas requiere tomar la decisión de gestionar, promocionar y respetar los derechos humanos, ésta será la mejor estrategia pedagógica para llevarla a las familias, comunidades, localidades y regiones. Construir la paz en la región andina nariñense es asumir la justicia, la libertad y el bien común como ejes transversales de la educación social, inclusiva y equitativa.

\section{Referencias}

Afanador Hernández, Claudia (2011, noviembre 6). Organización espacial de los Pastos coloniales. Academia Nariñense de Historia. Pasto: Colombia

Alto Comisionado para la Paz (2017). Acuerdo final para la terminación del conflicto y la construcción de una paz estable y duradera. Bogotá

Bajtín, Mijaíl (2003). La cultura popular en la edad Media y el Renacimiento. El contexto de François Rebeláis. Madrid, España: Ed. Alianza editorial. Tercera reimpresión.

Boff, Leonardo (2006). Ecología: Grito de la tierra, grito de los pobres. Brasil: Editorial trotta. 
Bonilla Castro, Elsy y Rodríguez, Penélope (2000). Más allá del dilema de los métodos. Bogotá: Ediciones Uniandes.

Calpa, Luis Eduardo (2011, noviembre 6). Nuevos relatos a partir de la escuela de pensamiento de Don Juanito Chiles en el Pueblo de los Pastos. Academia Nariñense de Historia. Pasto.

Cruz, Celia (1998). La vida es un carnaval (canción).

Geertz, Clifford (2003). La Interpretación de las culturas. España: Editorial Gedisa S.A.

Hernandez Buelvas, Zabier (2015). NARIÑO de la guerra a la paz. Realidades, roles y propuestas para el postdiálogo territorial. Bogotá: Editorial Teoría y Práxis

Huanacuni, Fernando (2010). Buen vivir/Vivir Bien. Filosofía, políticas, estrategias y experiencia regionales andinas. Lima: CAOI.

Mamián Guzmán, Dumer (2004). Los Pastos, en la danza del espacio, el tiempo y el poder. Pasto: Ediciones Unariño.

Martínez, Miguel (1999). La investigación cualitativa etnográfica en educación. Méjico: Ed. Trillas

Mesa Manosalva, Edgar (2016). El carnaval, escenario para el encuentro Intercultural. Carnivals in the world. Florencia, Italia: Editorial EDA.

Montenegro, Armando (2002). Una historia en contravía: Pasto y Colombia. Bogotá: Editorial Malpensante.

Muñoz A., Francisco et al. (1998). Estudio en Paz y Conflictos en las Universidades Andaluzas e Iberoamericanas. IPAZ, Universidad de Granada: Colección Eirene

Muñoz, Francisco y Molina Rueda, Beatriz (2004). Manual de Paz y Conflictos. España: Editorial Universidad de Granada.

Oficina del Alto Comisionada para la Paz (2017). Acuerdo final para la terminación del conflicto y la construcción de una paz estable y duradera. Bogotá: Primera edición

Papa Francisco (2015). Carta Encíclica Laudato Sí. Sobre el Cuidado de la Casa Común. Recuperado de: http://cort.as/-8i9C

Rojas Quiceno, Guillermo (2013). Índice de felicidad y buen vivir. Fundación Naturaleza, planeta y vida. España: Instituto Internacional del saber.

Rodríguez Rosales, Héctor (2005). El imaginario religioso popular de Nariño. Pasto: Biblioteca del centenario. 
Sanz Moncayo, Rafael (2006). Diccionario de la Lengua Pastusa. Pasto: Graficolor

Torres Carrillo, Alfonso (1995). Enfoques cualitativos y participativos en investigación social. Bogotá: UNAD.

UNESCO (1989). Recomendaciones sobre la Salvaguardia de la Cultura Tradicional y Popular.

UNESCO (2001). Declaración Universal sobre Diversidad Cultural, art. 1.

UNESCO (2003). Convención para la salvaguardia del patrimonio cultural.

UNESCO (1998). Resolución A/52/13). Cultura de Paz.

UNESCO (1999). Programa de Acción sobre una Cultura de Paz.

Zambrano, Carlos Vladimir (2006). Ejes políticos de la diversidad cultural. Universidad Nacional de Colombia. Bogotá: Siglo de Hombres Editores. 